\title{
Perp Walks as Punishment
}

\author{
Bill Wringe
}

Accepted: 20 October 2014 / Published online: 4 November 2014

(C) Springer Science+Business Media Dordrecht 2014

\begin{abstract}
When Dominique Strauss-Kahn, then head of the IMF, was arrested on charges of sexual assault arising from events that were alleged to have occurred during his stay in an upmarket hotel in New York, a sizeable portion of French public opinion was outraged - not by the possibility that a well-connected and widely-admired politician had assaulted an immigrant hotel worker, but by the way in which the accused had been treated by the American authorities. I shall argue that in one relatively minor respect, Strauss-Kahn's defenders were correct. They were correct to argue that the parading of Strauss-Kahn before the press, in handcuffs - the so-called perp walk - constituted a form of punishment; and thus that it contravened the principle that criminal punishments should only be administered after a fair trial. So-called 'expressive' theorists of punishment hold that a form of harsh treatment can only constitute a form of punishment if it has an expressive role. Within the expressive family, we can distinguish between views on which the primary target of the communication to be the society of which either offender, or victim, or both are members - what I call 'Denunciatory Views', and views which take the principle target of penal communication to be the offendersuch as Antony Duff's Communicative View. I shall argue that on both a minimal account of punishment and on either kind of expressive view, 'perp walks' are a form of punishment.
\end{abstract}

Keywords Punishment $\cdot$ Communicative theories $\cdot$ Antony Duff $\cdot$ Perp walks

\section{Introduction}

When Dominique Strauss-Kahn, then head of the IMF, and widely thought to be a leading contender in the forthcoming French presidential elections, was arrested on charges of sexual assault arising from events that were alleged to have occurred during his stay in an up-market hotel in New York, a sizeable portion of French public opinion was outraged (Baker and Erlanger 2011). They were outraged, not by the possibility that the allegations were true, and that a powerful, well-connected and widely-admired politician had assaulted an immigrant hotel worker, nor by the widely-reported suspicion that the accused had a well-known history

\footnotetext{
B. Wringe $(\bowtie)$

Department of Philosophy, Bilkent University, Ankara, Turkey

e-mail: wringe@bilkent.edu.tr
}

Bill Wringe

e-mail: billwringesemail@gmail.com 
of similar behavior to which members of the French political and journalistic elite had turned a blind eye; but by the way in which the accused had been treated by the American authorities (Davies 2011; Willsher and Rushe 2011).

Subsequent events - including the dropping of charges by the NYPD, and the surfacing of other allegations of sexual misconduct - make it difficult to sympathise with those who saw Strauss-Kahn as a victim; and much of what his defenders had to say, including the suggestion that the whole affair was a conspiracy aimed at removing a French leftwinger from his post at the IMF with the aim of replacing him with someone more congenial to American financial interests, and more or less explicit suggestions form the likes of Bernard-Henri Levy (Levy 2011) that it was beneath the dignity of an important public figure to be treated by the authorities as just another accused individual, evoked distaste at the time, and continue to evoke it in retrospect. To a large extent such distaste seems reasonable and healthy.

Nevertheless, those who defended Strauss-Kahn were correct in one relatively minor respect. The parading of Strauss-Kahn before the press, in handcuffs did constitute a form of punishment. For such a display to take place when Strauss-Kahn was merely accused, and had not yet stood trial, let alone been found guilty, contravened the principle that criminal punishments should only be administered after a fair trial. (They were, however, egregiously wrong to suggest that this would not have been true if an ordinary citizen citzien had been treated in the same way.)

\section{Theories of Punishment: An Overview}

In arguing that that perp walks constitute a form of punishment, I shall consider two kinds of view of punishment: those which involve what I shall call a 'Minimal Conception' of Punishment, and members of what I shall call the 'Expressive Family' of views. A wide range of views can be located within this conceptual space.

On the Minimal Conception of Punishment (henceforth MC) punishment is harsh treatment, inflicted on a wrongdoer or suspected wrong-doer, by an appropriate authority, in response to specifiable wrongdoing (cf Hart 1959). MC consists of four conditions which are individually necessary and jointly sufficient for a form of treatment's constituting punishment. I shall refer to these conditions as the MCPs. I refer to MC as a 'conception' of punishment rather than a definition or account, because its content is somewhat indeterminate. In particular, the notion of harshness could be spelled out in a number of ways. For example, we might take treatment's being 'harsh' to require that is actually harm an offender; or that it harm them in some specific way-for example, in ways that involve depriving them of liberty or in ways that infringe rights which they either have, or would have in circumstances in which they had committed no crime.

David Boonin (Boonin 2008) has recently put forward an account of punishment which seems closely related to MC. Boonin characterizes punishment as 'intentionally inflicted authorised retributive reprobative harm'. ${ }^{1}$ Boonin also requires that punishment involves 'intentionally inflicted harm'. This seems to be a way of making the idea that punishment must involve harsh treatment more determinate. (We shall also see in a moment that it does so in a somewhat problematic manner.) Boonin's requirement that punishment be 'authorized' corresponds to the third of MCPs. Furthermore, his discussion of the idea that punishment must be 'retributive' suggests that he takes this to require only that the punishment is a response to some specific wrongdoing: the second and fourth of the MCPs. What Boonin

\footnotetext{
${ }^{1}$ Boonin 2008 p23
} 
adds to the MCPs is the requirement that punishment be 'reprobative': in other words that it should express official condemnation of wrongdoing. This aligns him with the Expressive Family of Views, which I shall now discuss.

Advocates of the 'Expressive Family of Views' (henceforth EF) hold that MC ignores an essential feature of punishment: its expressive dimension. In particular they hold that a way of treating offenders only constitutes punishment if it satisfies both the MCPs and some further expressive condition or conditions. ${ }^{2}$ Duff 2009 I shall refer to such conditions as 'Putative Expressive Conditions', or PECs.

EF includes views on which the principle target of penal communication is the offender (Duff 2001) which I shall call 'communicative views'; and views where the primary target of the communication is the society of which either offender, or victim, or both are members ((Metz 2000), which I shall call 'Denunciatory Views'. EF can also includes two kinds of hybrid view. On Conjunctive Hybrid views, harsh treatment constitutes punishment only if it satisfies the MCPs and is intended to convey a message both to an offender and to a wider society. On Disjunctive Hybrid Views, a form of harsh treatment constitutes punishment provided it satisfies the MCPs and is intended to communicate something to either the offender or a wider society of which the offender is a part. (Wringe 2012). ${ }^{3}$

EF deserves particular attention in the current context for three reasons. First, the fact that members of EF place more constraints on what can counts as punishment than MC makes it harder to establish perp walk are punishment on such views. Ignoring EF in this context would leave room for the suspicion that the defense of this conclusion depends on an unduly broad conception of punishment. Secondly, it is at least arguable that those who think that punishment by the state can be justified in at least some cases should accept some version of EF. Finally, EF puts us in a position to make a more nuanced judgment as to which other supposedly non-punitive features of the criminal justice system might also constitute cases of punishment than MC does.

\section{Circumventing Abolitionism}

David Boonin (Boonin 2008) has recently argued that the practice of state punishment cannot be justified. Call this view 'abolitionism'. As we saw in Section II Boonin, characterizes punishment as 'intentionally inflicted reprobative harm' introduced above. His arguments for abolitionism involve showing that none of the standard defenses of punishment provides an adequate justification for the intentionally inflicted harm that punishment involves. ${ }^{4}$

\footnotetext{
${ }^{2}$ On my taxonomy a view will only count as a member of the 'Expressive Family' if it is one on which it is constitutive of something's counting as punishment that it have an expressive dimension (Feinberg 1970, Duff 2011, Wringe 2013). Someone might hold a view on which something counted as a form of punishment simply by satisfying the MCPs, but on which its justifiability depended on various expressive features. Since I shan't be much concerned with questions of justifiability, the taxonomy I have used is the one which best fits my purposes here.

${ }^{3}$ Advocates of expressive views also differ as to content which must be communicated if a form of harsh treatment is to constitute punishment: they may hold that it should relate to the wrongness of the perpetrator's action; the worth of the victim or victims (if there are any) and the unwillingness of a society to tolerate wrongdoing of the sort in question (Hampton 1992; Duff 2001; Bennett 2006, 2008; Wringe 2013). These differences, while significant will not affect my argument here.

${ }^{4}$ As Wringe 2013 p 864 notes, it's essential to Boonin's case that the harm here be intentionally inflicted and not merely foreseeable since he advocates replacing (what he calls) punishment with measures such as compulsory restitution to victims which involve foreseeable harm to victims
} 
We should not assume that abolitionism is false. However, we should notice two things. First, if abolitionism is true, then the question of whether perp walks constitute a form of punishment is comparatively uninteresting: our existing institutions are in need of more wholesale reform than the abolition of perp walks would entail. Second, many people- both philosophers and ordinary citizens - take abolitionism to be false. So for the purposes of this paper it is worth devoting particularly careful attention to philosophically plausible views which do not have this consequence.

Elsewhere (Wringe 2013) I have argued that advocates of members of EF need not accept Boonin's arguments for abolitionism. This is because they need not accept that punishment involves intentionally inflicted harm. They must hold that treatment of offenders must be harsh. However they can understand harsh treatment to be treatment of a type that could reasonably be expected to make individuals of the same type as the offender suffer. (Wringe 2013 p 867) On this understanding of harshness, I can inflict harsh treatment on an individual without intending to make them suffer; and if, in punishing someone, I inflict harsh treatment on them without them coming to suffer, I need not necessarily have failed in anything that I set out to do. Nevertheless it is in no way an accident that punishment should typically cause those on whom it is inflicted to suffer.

Although this characterization of harshness is available to advocates of $\mathrm{EF}$, it is not available to advocates of MC. If we understand punishment along the lines of $\mathrm{MC}$, then interpreting harshness in the way I suggest has counter-intuitive consequences: it appears to entail that the arrest and pre-trial detention of criminals; self defense; the defense of others against attacks on them; just warfare; and court ordered forcible restitution of property by offenders all constitute forms of punishment (cf Wringe 2013 p869).

One might argue that some of our intuitions as to what is and what is not punishment may be awry, counter-intuitive consequences should count against the acceptability of a characterization of punishment when there are alternative characterizations available which do not have these counter-intuitive consequences. In this case there are. Expressivists can adopt my characterization of harshness while denying that these forms of behaviour constitute punishment: they can deny that these forms of behaviour satisfy the PECs outlined in Section II (cf Wringe 2013 pp 870ff).

\section{Minimal Conditions for Punishment (1): Harsh Treatment}

Many philosophers hold that something can only constitute a case of punishment if it involves harsh treatment of someone who is taken to have committed an offense. ${ }^{5}$ On an everyday understanding of the notion of harshness, perp walks will typically involve harsh treatment. They are liable to be experienced as humiliating and shameful, and in many cases - perhaps

\footnotetext{
5 One referee for the journal suggested that the 'harsh treatment' condition should be understood as requiring that punishment involve harsh treatment inflicted on someone who has been convicted of an offense. On this view perp walks of the sort I am concerned with would not constitute punishment. I find this view unhelpful, since it obscures rather than clarifies the role which conviction plays in the legal system. We typically take conviction to play a role in making it legitimate to treat someone in a way in which it would not otherwise be legitimate to treat them. This point is naturally expressed by saying that conviction legitimates punishment. On the referee's suggested way of seeing things we cannot say this. We might say instead that conviction legitimates punishment* where punishment* is anything which satisfies all the conditions for being punishment other than the condition of being imposed on a convicted offender. Those who are attracted to the referees way of seeing things are invited to substitute 'punishment*' for 'punishment' throughout this paper until Section XI. The practical upshot-that this form of treatment is illegitimate-will be the same.
} 
including the one involving Strauss-Kahn which I described at the beginning of this paper it seems plausible that they are intended in precisely this way.

One might hold that punishment must involve some sort of abridgement of someone's rights; or a restriction on someone's liberty. ${ }^{6}$ I shall treat these as ways of specifying the notion of 'harshness' involved in the MCPs more precisely. Whatever the merits of such accounts of punishment, they do not seem to present any special obstacle to the view that perp walks constitute a form of punishment. First notice that, on pain of implausibility, the notions of 'restriction of liberty' and 'infringement of rights' must be understood in a way that avoids entailing that posttrial imprisonment is not a form of punishment. It is hard to interpret these ideas in a way which means that post-triqal imprisonment is not a form of punishment but that perp walks are.

Thus one might argue that perp walks involve an infringement of relatively uncontroversial rights, such as a right of freedom of movement or of freedom of association. However, many people hold that an individual's rights in these areas are not necessarily taken to have been abridged when their exercise is made subject to the constraints of duly-made law. (For example, the existence of speed limits in built-up areas is not reasonably understood as involving an infringement of my right to freedom of movement.) Someone might hold that the sorts of restrictions on movement and association that perp walks involve can be appropriately understood in an analogous way. However on a view of this sort it is not clear that post-trial imprisonment constitutes an infringement of rights, since the restrictions that those who are imprisoned undergo are imposed by duly imposed law.

Similarly, perp walks seem to involve restrictions on an individual's liberty, since involve fairly obvious constraints on an individual's capacities for unconstrained movement. Someone might propose a conception of liberty under which such constraints did not necessarily amount to a restriction of liberty properly understood. Consider, for example, Hobbes' view of liberty, on which physical constraints on movement only restrict my liberty when I am trying to escape. However it is not clear that someone could propose a view of this sort on which posttrial imprisonment did count as a restriction of liberty. (As, on Hobbes view, it does not).

Some philosophers hold that punishment must involves an intention to cause suffering to the individual on whom it is inflicted. (Hanna 2008, 2009a, b; Boonin 2008). We might regard this as a way to further specify the notion of harshness involved in the MCPs (cf Hanna 2008). However, I have already argued in Section II that this conception of punishment is unsatisfactory, at least in the context of the current debate. So we should not understand notion of harshness in this way.

\section{Minimal Conditions of Punishment (2): Response to Specifiable Wrongdoing}

Even if perp walks do involve harsh treatment, we might nevertheless wonder whether involve a response to 'specifiable wrongdoing'. There are two questions to consider: 'Can perp-walks be seen as a response to wrongdoing, rather than something less, such as the suspicion of wrongdoing?' and 'Can they be regarded as responses to specifiable wrongdoing?' 7

\footnotetext{
${ }^{6}$ I thank an anonymous referee for this suggestion.

${ }^{7}$ Someone might argue that even if perp walks are not responses to specifiable wrongdoing, it is sufficient for a critic of the practice to establish that they are a response to a suspicion of wrong-doing, and then to argue that they are a form of treatment which is analogous to punishment but which is inflicted when a much lower evidential burden is met. I think that a full exploration of this line of argument would require a consideration of the role that the existence of a strong evidential burden plays in justifying the harsh treatment punishment involves. Space precludes me from discussing these complex issues in detail. However, I am grateful to a referee for this journal for suggesting this line of though.
} 
Perp walks can be inflicted on individuals who are, in fact, innocent of any offence. Someone might conclude from this that they cannot be a response to wrongdoing. This argument presupposes that something cannot be a response to wrongdoing if it can occur without any actual wrongdoing taking place. However, this conception of a response to wrongdoing differs from the one intended by someone who holds that punishment must be a response to wrongdoing. Consider the case of an innocent person who is found guilty, and has penal sanctions inflicted upon them. We should not deny that in such a case an innocent person was being punished. If we did, we would be unable to say that they were being wrongly punished. ${ }^{8}$

The notion of a response to wrongdoing, which is required in this context is normatively freighted. On this conception It follows from As being a response to B that the occurrence of B is regarded as a reason for A. This does not entail that A cannot occur without B having occurred. It entails that if B occurs without A having occurred, a mistake has been made.

The penal sanctions we impose on those found guilty by the courts are correctly understood as responses to wrongdoing in this sense. In a civilized society, the fact that someone is shown to have been innocent of a crime which they are alleged to have committed is regarded as a reason for making some kind of public acknowledgment of their innocence and the wrongfulness of having inflicted harsh treatment on them.

Some societies find it difficult to make the kind of public acknowledgment which a conception of punishment as a response to wrongdoing seems to call for in such cases. ${ }^{9} \mathrm{We}$ might extrapolate from this to the possibility of a society which never acknowledges mistakes of this sort: for example, a society with legal institutions which do not allow even for the possibility of appealing against a sentence. If my view entailed that a society of this sort could no be regarded as punishing people, it would be unacceptably counter-intuitive.

Fortunately, it does not. We should distinguish possible cases here. One is a society which acknowledges the potential fallibility of its legal institutions and pays lip-service to the idea that, ideally speaking the innocent should not be punished, and appeals to the imperfection of all practicable human institutions to justify the view that on the whole, it is better if those who are found guilty are not exonerated. Here it seems appropriate to think of sanctions being imposed as a response to wrongdoing, and hence that the society has institutions of punishment - albeit ones which are badly awry. More fantastically, perhaps, we can imagine a society which does not countenance the possibility of judges making mistakes. Here too, we might legitimately regard sanctions as being imposed in response to wrongdoing, and so as constituting something which we can recognize as punishment, although the case is sufficiently alien that in doing so, one might be moved to comment on some of the ways in which the institutions of this society differ from our own.

Here is a more difficult case. Judges are known and acknowledged to be fallible. However there is no institutional basis for recognizing cases where mistakes have been made, and no acknowledgment that mistakes of this sort present even a prima facie reason for suspending sanctions, acknowledging that they have been wrongly imposed, or compensating those on

\footnotetext{
${ }^{8}$ Someone might argue that the relationship between 'wrongful punishment' and punishment proper should be seen as analogous to that between a rubber duck and a real duck. Rubber ducks provide no counter-example to the claim that ducks are living creatures - they are things which merely purport to be ducks. Some instances of wrongful punishment might be understood that way-for example, ones in which harsh punishment is inflicted in full knowledge of the innocence of the supposed perpetrator. But not all instances of the punishment of the innocent are like that.

${ }^{9}$ Consider Lord Denning's notorious remark, concerning the later-exonerated 'Birmingham Six' that to accept that the police had given false testimony against them would open an 'appalling vista'. (In fairness, it should be noted that Denning later recanted this view.) (Dyer 1999).
} 
whom they are imposed. We might deny that in this case sanctions are being imposed as a response to wrong-doing: it seems as though they are, rather, imposed as a response to justified suspicion of wrongdoing. What makes the difference is that in a case like this, there seems no reason for anyone to think that those who have imposed the sanction take themselves to have acted inappropriately in the absence of actual wrongdoing.

These hypothetical cases are intended to shed light on the question of whether perp walks can be regarded as a response to wrongdoing or merely as a response to suspected wrongdoing. If they are analogous to the first kind of case then the answer is 'Yes'. If they are analogous to the third kind of case the answer appears to be 'No'. (It seems fairly clear that they are not analogous to the second kind of case.) One might suppose that they are analogous to the third kind of case, insofar as there seems to be little institutional scope for public acknowledgment of cases of wrongful arrest.

However, matters are not quite so simple. It is not plausible to suppose that there is nothing normatively inappropriate about individuals who turn out to be innocent being subjected to perp walks. Admittedly, the idea that law enforcement officials should admit that they have made a mistake in such cases might not seem to enjoy much popular support . However, we should not make too much of this. One thing we might want to consider is that a formal finding that an individual is not guilty is itself a public acknowledgment of the sort we are looking for.

Of course, not all those who are arrested on grounds of reasonable suspicion without being found guilty end up being acquitted in a court of law: sometimes charges are dropped, and a case does not come to trial. Does our practice in such cases undermine the case for seeing perp walks as a response to wrongdoing rather than to the mere suspicion of wrongdoing? It need not. An alternative understanding of our practice, would be one on which we take it that the prima facie case for acknowledging that a sanction has been wrongly imposed is outweighed by public policy considerations, such as the importance of not undermining either the morale of law-enforcement officers or the trust that the public places in them. ${ }^{10}$ This way of seeing things would make cases of this sort analogous to the first kind of fictitious case I discussed above.

I have argued that perp walks should be seen as involving a response to wrongdoing, rather than as a response to the reasonable suspicion of wrongdoing. One might, nevertheless wonder whether they can be seen as a response to specifiable wrongdoing. One prima facie point in favour of the idea that they can is that in may countries individuals enjoy various kinds of constitutional and legal protections against arbitrary arrest. Such provisions normally require that arrests should only take place on the basis of some reasonable cause. Requirements that individuals should be charged with a specific offense within a given time frame add to the case for thinking that insofar as we shave something which is a response to wrongdoing it is a response to specifiable wrongdoing.

However individuals are not always tried for offenses they are initially charged with. Practices such as plea-bargaining can only make sense in a system were this is both true and publicly acknowledged. This fact might appear to undermine the idea that perp walks involve a response to specifiable wrongdoing. It might seem as though they are better understood as involving a response to wrongdoing somewhere in the vicinity of the offense with which the individual is charged. This point is less significant than it might appear at first sight. The fact that an individual need not be prosecuted for an offence that they are initially charged with need not indicate that the perp walk is not intended as a response to that kind of wrongdoing. It shows only that, if convicted, their sentence is not a response to the same wrongdoing that their

$\overline{{ }^{10}}$ This is not to concede that such considerations should be decisive, but simply to acknowledge the possibility that in may cases they are. 
initial treatment was. This is not especially paradoxical. There would only be a paradox if we wanted to maintain that the perp walk and the eventual punishment should be seen as responses to the same wrongdoing. Someone defending my view should not claim this: apart from anything else it would be difficult to see what we should say about individuals who ended up not being charged at all, and individuals who were subsequently found innocent.

\section{Minimal Conditions of Punishment (3): Appropriate Authority}

Let us now consider the 'appropriate authority' component of the MCPs. It is tempting to say that an appropriate authority is simply an authority which has the right to inflict punishment. We could then argue, that perp walks are not punishment, simply on the grounds that they involve treatment which is typically inflicted by agents of law enforcement such as the police, and that it is not properly part of the police's role to inflict punishment. However, if the appropriate authority condition is intended as part of a definition of punishment, we cannot understand it in the way suggested, on pain of circularity. ${ }^{11}$

Someone might claim the police are accorded authority to investigate crimes and to arrest suspects but not to subject them to humiliating treatment. They might then deny that humiliating treatment of the sort we are considering here is punishment, since the police are not authorised to treat people in this way. Someone who held this view would owe us a noncircular account of the appropriate authority condition. This account would be one on which the question of whether the appropriate authority condition was satisfied would depend not only on the status of the person inflicting the treatment, but on whether they had the authority to inflict treatment of precisely that sort.

We should not accept an account of this sort. Consider a case in which the death penalty (or some other way of treating the convicted) is ruled unconstitutional under an existing constitution. If it is unconstitutional, no judge had the authority to impose it. It contributes neither to clarity nor to justice to claim that those on whom it was inflicted were not punished. But this is what the suggestion commits us to.

Here is a non-circular explication of the notion of an appropriate authority. An authority is 'appropriate' in this context when and only when it has been accorded the right to inflict harsh treatment of the sort in question. To say that an individual or group is accorded a right is to say that they are regarded as, or acknowledged as having the right by some group who acknowledge the set of rules which specify the offense for which the individual is being punished. ${ }^{1213}$

If the 'appropriate authority' condition is understood in this way, perp walks will often satisfy it. They are public events, which are taken to be legitimate by law enforcement officials, by journalists and photographers, and by the public at large. They are not challenged in the

\footnotetext{
${ }^{11}$ This point does not preclude us from turning the argument round. If we establish that perp walks are punishment, this would be a reason for denying that law enforcement officers should subject suspects to them, provided we had independent grounds for saying that law enforcement officers should not be in the job of meting out punishment.

${ }^{12}$ It does not follow from the fact that an individual or group of individuals is accorded or acknowledged as having a right by a group that they actually do have such a right. So understanding the 'appropriate authority' condition in the way I suggest, does not foreclose the possibility that either individual instances of punishment, or our punitive institutions as a whole might turn out to be illegitimate.

${ }^{13}$ It follows that 'appropriate' authorities may include all kinds of bodies that we might not normally regard as having the right to inflict legal punishment - teachers, parents, sports referees, gang bosses and so on. I take this to be a positive feature of my account: it seems plausible that penalties inflicted for rules infractions by such individuals are rightly referred to as punishments, even if they cannot be justified in the same ways that we take legal punishment to be justified. (Cf Duff 2001: for a contrasting view, see Brooks 2012).
} 
courts; and they only rarely attract critical public commentary. Furthermore, since there is no attempt to hide what is going on, we cannot classify them as events which are merely tacitly condoned, while being formally frowned on. In short, everything suggests that we do accord to law enforcement officials the right to inflict this treatment on those suspected of wrongdoing.

\section{The Putative Expressive Conditions}

I have now argued that perp walks could be seen as satisfying the MCPs. Since it is normally inappropriate for officials of a state, acting in their capacity as representatives of the state to inflict punishment prior to a criminal trial, those who think that the MCPs provide us with an adequate characterization of punishment ought to find the institution problematic.

However, one might hold that the MCPs give us an inadequate characterization of punishment. There are practices which seem to be unavoidable from a practical point of view - and to that extent morally justifiable - if the law is to be enforced at all and yet conceptually distinct from punishment. Consider, for example, the arrest and pre-trial confinement of by the state of those suspected of wrongdoing. On my account of harshness (Wringe 2013) it is also inflicted by an appropriate authority; and is, also plausibly characterized as a response to wrong-doing, in the normative sense of response which I outlined in Section IV.

The view that the arrest and pre-trial detention of suspected criminals constitutes a form of punishment is unattractive. We can avoid it by appealing to Feinberg's suggestion that a form of harsh treatment only constitutes punishment if it has a significant expressive dimension.(Feinberg 1970) Several recent authors have developed this thought, in slightly different ways. For example, Antony Duff (Duff 2001) has argued that it is essential to a form of treatment's constituting punishment that it should be intended to communicate to an offender that they have done something wrong, with the further intention of offering an occasion for remorse or regret on the part of wrongdoer. Similarly, for Christopher Bennett (Bennett 2008), the harsh treatment which punishment involves is an occasion for a criminal to engage in a state-sponsored form of symbolic penance. Forms of harsh treatment which do not have this communicative function are, to that extent not genuine cases of punishment. ${ }^{14}$ And on a denunciatory view, like that of Thad Metz (Metz 2000), punishment should involve an intention to communicate with a wider public a message about the punishing authority's attitude to the crime. ${ }^{15}$ Again, this account enables us to see why arrest and pre-trial confinement need not constitute a form of punishment.

Does an appeal to the PECs provide us with grounds for denying that perp walks are a form of punishment? I shall argue that it does not. In Section VII, I shall consider denunciatory members of the Expressive Family, In Section VIII I shall consider communicative members of the family; and in Section IX I shall conclude by considering hybrid views.

\section{Punishment: Denunciatory Accounts}

I shall use the label 'denunciatory' to refer to any account of punishment on which i) the expressive goals of a form of harsh treatment are essential to classifying it as punishment and

\footnotetext{
${ }^{14}$ Some forms of harsh treatment which do not have this function might nevertheless, masquerade as punishment: they might go by that name and be mistakenly regarded as legitimate because of their resemblance to practices which were genuine cases of punishment.

${ }^{15}$ Cf also Wringe 2006
} 
ii) it is sufficient for the treatment's counting as punishment that it should include among the intended recipients of the message communicated members of a political community subject to the law in response to a violation of which the harsh treatment is imposed other than the person being punished.

We should notice two things about this characterization of denunciatory accounts of punishment. First, the characterization says nothing about the content that has to be expressed by the harsh treatment. We need not assume, for example, that it involves shaming the offender. In fact, we need not assume that what is expressed is something about the offender, except insofar as they are the person who has committed a particular act. Secondly, we need not assume that on a denunciatory account, punishment can have no other goals than that of expressing a message of a particular sort - or even that it can have no other communicative goals. (Thus, what Thom Brooks (Brooks 2012) has called a 'unified' theory of punishment, on which punishment is justified insofar as it achieves one of a number of different goals, might still count as a denunciatory account in my terms.)

Perp walks seem to be cases of punishment on a denunciatory account of punishment. The purpose of the perp walk seems to be, precisely, to display the individual who is subjected to it as being someone who has behaved in such a way as to merit investigation and custody. Furthermore, at least in cases like Strauss-Kahn's the intended audience seems to includethough it need not be limited to - members of a political community who are subject to the law that the individual in question is accused of breaking.

One might resist this conclusion in one of two ways. First one might argue that although the perp walk does have an expressive purpose, the expressive purpose which it involves is entirely legitimate. It is that of communicating to the public the fact that one particular individual is being investigated.

I have characterized denunciatory accounts of punishment in a way which entails that if perp walks had this expressive purpose they would still be a form of punishment. Someone might respond that this shows that my characterisation of denunciatory accounts of punishment was misguided. For it might seem as though on this account, any communication of the relevant facts about an individual who was under arrest could come to count as punishment. There would surely be something wrong about a view on which a legitimate prohibition on individuals being punished without trial should prevent authorities from allowing people to know who they were investigating.

However, this is a mistake. On my characterization of the denunciatory account the MCPs are necessary conditions for something's counting as punishment. There are many ways in which the relevant information could be communicated that would not count as harsh treatment, and which would, therefore, not satisfy the MCPs. (For example, the names of offenders and their offenses might be entered in a database on a publicly available webpage. There might be classes of offenders whose typical members were unfazed by this. On my 2013 account of harshness, they would not be harshly treated).

Someone might resist the conclusion that on a denunciatory account perp walks should count as a form of punishment on different grounds. They could argue that although perp walks do involve putting a putative offender on display before a certain kind of audience, they do in a way that makes the role of that audience, and communication with that audience incidental and inessential. The idea here would be that the perp walk was aimed at making the offender feel ashamed. On this account it would be true that perp walks had an expressive purpose, but it would be an expressive purpose on which the intended recipient of the message was not a wider political community, but the putative offender him or herself. On this view perp walks would not necessarily meet the conditions for constituting a form of punishment, as conceived by denunciatory accounts. 
However, this response is unsatisfactory. Suppose the purpose of perp walks is to shame putative offenders. The mechanism envisaged for bringing this about is one whereby the individual comes to feel shame because they recognise that a certain audience regards them in a particular way. If the recognition of this fact is part of the mechanism that is intended here, then perp walks have an expressive goal which involves communicating something to an audience. If they did not do so, then the envisaged mechanism could not work: there would be nothing of the right sort for the offender to recognize. So a denunciatory account of punishment can cover cases of this sort.

Here is an objection. There are ways of inducing shame in a putative offender which would not involve their recognition that a particular audience sees them in a particular way. (For example, one might try to get a putative offender to imagine that a certain audience sees them in a particular way.) So even if perp walks are aimed at shaming putative offenders, doing so need not involve communicating a message to a wider audience. It may be enough that the putative offender believe (or even imagine) that they are so seen. Since perp walks could achieve the goal of getting putative offenders to feel shame without succeeding in communicating a message about the shamefulness of the putative offender to that audience, someone who aims to shame an offender by making them engage in a perp walk need not intend to communicate a message to an audience.

We can certainly imagine cases in which putative offenders end up feeling shame, even though they are mistaken about how they are seen by an external audience. However this is not enough to show that the institution of the perp walk doesn't involve an intention to communicate with such an audience. It is a case of someone achieving a goal by an unintended means. The objection requires us to imagine a situation in which perp walks were intended to produce shame in putative offenders without an intention to communicate anything to an audience.

Consider another kind of case: a society in which it is widely known among those who engage in law enforcement that members of the public are more or less indifferent to displays of putative offenders, but where this is not typically known to those arrested, so that the perp walk is a reliable means of inducing shame in offenders. Here the perp walk could be intended to induce shame in perpetrators without there being an intention to convey anything to an audience.

It is hard to see how this kind of situation could be stable: to imagine it, we need to imagine a society in which there is no overlap and little social commerce between arrestees and law enforcement officials. The society being imagined also would be one in which there was an extreme lack of transparency in its social institutions. If we concede that in such a society, perp walks would not be a form of punishment, we are not making the same concession about actual societies, or any society we should want to live in.

We might think that if we think that perp walks are a form of punishment in our society, then we should be prepared to count closely analogous forms of treatment in imaginably different forms of society as forms of punishment as well. This approach begs the question against denunciatory forms of punishment. It is tantamount to insisting that questions about how a certain form of treatment is understood by society at large are irrelevant to whether or not we should classify something as punishment. Someone who holds this, but is nevertheless attracted to a views about punishment which falls within the 'expressive family' may need to consider an alternative view such as the communicative view.

\section{Communicative Accounts}

I have contrasted 'denunciatory' with 'communicative' versions of expressivism by reference to the intended recipients of the message which the harsh treatment which punishment involves is supposed to convey. On a communicative account, the intended recipient is the 
individual on whom harsh treatment is inflicted. The most prominent contemporary advocate of such a view is Antony Duff. (Duff 2001, 2009)

Duff holds that it is partially constitutive of a form of harsh treatment's constituing punishment that it should have an expressive dimension. He also holds that the harsh treatment which punishment involve should be aimed at bringing about remorse and or regret on the part of the offender. One might think that, on this view there would be a fairly straightforward strategy for arguing against the claim that perp walks are a form of punishment. For one might argue that perp walks are not, or need not have such an aim. The case for thinking this might be bolstered by some of the considerations put forward in the previous section in favour of the claim that the intended audience in such a case is not the perpetrator, but the community at large.

This would be a good argument if we construed Duff's view as being one on which it was not only constitutive of something's being punishment that it should have an expressive dimension, but also constitutive of its being punishment that it be intended to express a message of a particular sort to a particular recipient. However, this seems implausible. ${ }^{16}$

Here is a more plausible alternative. Suppose we distinguish carefully between the project of explaining what punishment is and the project of explaining why it is sometimes justified. Then there are two distinguishable claims we might make about the expressive dimension of punishment, one broader and one more narrow. The broader claim is that punishment must have an expressive dimension; the narrower one that it must be intended to express a message of a certain sort to a certain audience.

Duff seems to be committed to regarding the broader expressive claim as being one which articulates something which is partly constitutive of punishment (Duff 2009). However, it seems possible to do so without regarding the second claim as also being partly constitutive of punishment. One might instead regard it as something which needs to be the case in order for certain forms of punishment to be justified.

This view seems at least as well supported as an account on which narrow expressive claims are built into the definition of punishment. The sorts of arguments which expressivists typically rely on to support the claim that punishment must have an expressive dimension, such as Feinberg's appeal to the distinction between punishments and taxes, seem unable to support the suggestion that particular communicative goals must be constitutive of punishment (Feinberg 1970). Furthermore a view on which the narrower claims about punishment are seen as partially constitutive of something's being punishment seem to run in to difficulty when we consider cases such as capital punishment. On a reading of Duff's view where the narrow expressive conditions are constitutive of punishment, many cases of capital punishment might fail to constitute punishment at all. This seems implausible. By contrast, on the account which I am proposing we can hold that capital punishment is indeed punishment, but it is a form of punishment which will almost always be unjustified. ${ }^{17}$

On this way of understanding Duff's view, perp walks can also count as a form of punishment. And if Duff is right about the conditions which must be satisfied for a form of punishment to be justified, they will, in many cases, be problematic from a normative point of

\footnotetext{
${ }^{16}$ One reason why it seems implausible is that the sorts of communicative intentions that Duff has in mind seem to be closely bound up with notions of repentance and forgiveness which seem to be far from being culturally universal. Thus, for example, Konstan (2012) argues that the notion of forgiveness cannot be found among the ancient Greeks, in early Judaism or even in the Church fathers. It seems implausible to claim that punishment was unknown in such societies.

${ }^{17}$ A further reason for taking the communicative view in the way I have suggested is that it makes it easier to see how certain non-paradigmatic cases of punishment, such as the punishment of war criminals and business corporations might constitute punishment. For discussion, see Wringe 2006; Wringe 2012.
} 
view for two distinct reasons. They will be unjustified both because they are inflicted in advance of a criminal trial and because they aim at sending a message to the wrong recipient.

\section{Hybrid Views}

In Section II I introduced and defined two kinds of 'hybrid' members of EF: disjunctive and conjunctive hybrids. On a disjunctive hybrid view, it will be sufficient for a form of harsh treatment which satisfies the MCP's to constitute punishment that it be directed at an audience consisting of members of the political community to whom the offender belongs. In other words, a disjunctive hybrid view is just a particular version of a denunciatory view as that is defined in Section VI. So the arguments I have used to show that denunciatory accounts entail that perp walks are a from of punishment apply without modification.

Conjunctive hybrid views raise more difficult concerns. Since they are not versions of the denunciatory view, the arguments of Section VI do not show that on such views perp walks must be a form of punishment. However, there is more to say. In Section VII, I argued against views on which it is a necessary condition for a form of harsh treatment's constituting punishment that it should be aimed at expressing a message to an offender. I suggested that views of this sort were a less satisfactory way of developing the underlying insights of the communicative view than views on which the fact that the message expressed was to an offender played a role in justifying the institution of punishment, but was not constitutive of that institution. Conjunctive hybrid views are views on which this is a necessary condition of a form of harsh treatment's constituting punishment. So the points made in Section VII apply to them as well. The possibility of such views makes relatively little difference to my analysis as a whole.

\section{Concluding Remarks}

I have argued that on both a minimal conception of punishment and on the most plausible members of the expressive family we should regard perp walks as constituting a form of punishment. We might wonder what the practical upshot of this conclusion is. Does it follows that there is something morally objectionable about the practice?

It does. One quick route to this conclusion would be to argue that it is wrong to punish someone without a fair criminal trial. But there is a natural follow-up to this question. We might ask what it is about criminal trials which make them rather than any other form of investigative procedure, the necessary preliminary to legitimate punishment. This question might seem especially pressing when we bear in mind that individuals do not become the subject of criminal indictments on the basis of mere suspicion. One might think that there is good reason to think that many indicted criminals are guilty of something even before a formal finding of guilt has been made.

Any adequate answer to this question would require something which goes well beyond the current paper: namely a theory of the criminal trial. Such a theory would contain at least two parts. First, it would explain what distinguishes criminal trials from other forms of proceeding. One plausible form of answer would make reference to the requirement for a particularly high standard of proof Secondly, it would explain why there is a normative link between this distinctive form of trial and liability to punishment. I leave it as an open question how an advocate of a denunciatory account of punishment might answer this question.

We might also ask whether the account I have put forward has any other practical implications. It is at least plausible some other common forms of law enforcement practices 
- such as the widespread distribution of suspects' mugshots and their detention in prison-like conditions - might be subject to the same form of criticism. ${ }^{18}$ The same might also be true of some aspects of the trial process - for example, the setting of the court room, the entering of formal pleas, and the fact the plea made is that of 'not guilty' rather than 'innocent'. 1920

It is worth entering two caveats here. One is that the extent to which an expressive theory of punishment requires us to regard these features of the criminal justice process as forms of punishment is likely to depend to some extent on the details of the expressive theory. Thus, for example it will be hard to defend the view that aspects of the treatment of those who are being detained for trial that are not widely known should be regarded as having a denunciatory function (though they might have a communicative function).

A second caveat anticipates a further objection. Someone might worry that if we pursue the analysis proposed in this paper to the fullest extent possible, it will turn out that so many aspects of our system of criminal justice turn out to be forms of punishment that avoiding pretrial punishment might involve giving up on the pursuit of criminal justice at all.

This would be so, for example, if arresting a suspect constituted a form of punishment - a consequence which might be thought to constitute a reductio of the view proposed here.

This line of argument seems more likely to succeed when directed at versions of MCP than members of EF. I noted in Section VII, that one advantage of members of EF is that they leave room to argue that pre-trial detention of suspected offenders need not count as punishment. Something similar seems to be true of arresting a subject: there seems no need to assume that it must have either a communicatory or a denunciatory function (although it may be carried out in a way which ensures that it does.) It may nevertheless turn out that in practice certain aspects of our system of criminal law enforcement do impose punishments where they should not do so. If so, they need and deserve reform. ${ }^{21}$ But to concede this is not to concede the full force of the objection. 22

\section{References}

Baker A, Erlanger S (2011) IMF chief, apprehended at airport, is accused of sexual attack New York Times May 14 2011:http://www.nytimes.com/2011/05/15/nyregion/imf-head-is-arrested-and-accused-of-sexual-attack. html? r=0. Accessed 24 February 2014

Bass G (2002) Stay the hand of vengeance: The politics of war crimes trials. Princeton University Press, Princeton

Bennett C (2006) State denunciation of crime. J Moral Philos 3:288-304

Bennett C (2008) The apology ritual. Cambridge University Press, Cambridge

Boonin D (2008) The problem of punishment. Cambridge University Press, Cambridge

Brooks T (2012) Punishment. Routledge, London

\footnotetext{
${ }^{18} \mathrm{I}$ am indebted to an anonymous referee for this journal for this suggestion

${ }^{19} \mathrm{I}$ am indebted to a (different) anonymous referee for these suggestions and to Duff 1986 for the general suggestion that the trial has an expressive dimension.

20 Bass 2002; Luban 2006 and Wringe 2006 all suggest that war crimes trials have an important expressive dimension, which is relevant to their justifiability. The same may also be true of trials of other high-profile public figures. If this is correct, then it is also important to ensure that the expressive dimensions of such trials do not transform them into instances of punishment without trial.

${ }^{21}$ It is also worth observing that the criminal trial in particular can be regarded as having features such as the presumption of innocence whose expressive dimension seem to go some way towards distinguishing it from anything that might be regarded as a form of punishment

22 I would like to thank Sandrine Berges, Nathan Hanna, Saladin Meckled-Garcia, Ambrose Lee, an audience at the 2013 meeting of the Association for Social and Legal Philosophy and two anonymous referees for this journal for comments on earlier drafts of this paper.
} 
Davies L (2011) 'How Dominique Strauss-Kahn's arrest awoke a dormant anger in the heart of France's women' The Guardian May 22 2011, retrieved from http:/www.theguardian.com/world/2011/may/22/dominiquestrauss-kahn-arrest-dormant-anger-france-women. Accessed 22 February 2014

Duff RA (1986) Trials and punishments. Cambridge University Press, Cambridge

Duff RA (2001) Punishment, communication and community. Cambridge University Press, Cambridge

Duff RA (2009) 'Can we punish the perpetrators of mass atrocities'. In: Brudholm T, Cushman T (eds) The religious in response to mass atrocities. Cambridge University Press, Cambridge

Dyer C (1999) 'Lord Denning, controversial 'people's judge', dies aged 100' The Guardian March 61999 http:// www.theguardian.com/uk/1999/mar/06/claredyer1. Accessed 12 February 2014

Feinberg J (1970)'The expressive function of punishment'. In: Doing and deserving Princeton University Press, Princeton

Hampton J (1992) Correcting harms versus righting wrongs: the goal of retribution. UCLA Law Rev 39:16591702

Hanna N (2008) Say what? A critique of expressive retributivism. Law Philos 27:123-150

Hanna N (2009a) Liberalism and the general justifiability of punishment. Philos Stud 145:325-349

Hanna N (2009b) The passions of punishment. Pac Philos Q 90:232-250

Hart H (1959) Prolegomena to the principles of punishment. Proc Aristot Soc 60:1-26

Konstan D (2012) Before forgiveness. Oxford University Press, Oxford

Levy BH (2011) Bernard-Henri Lévy Defends Accused IMF Director The Daily Beast May 15 2011. http://www. thedailybeast.com/articles/2011/05/16/bernard-henri-lvy-the-dominique-strauss-kahn-i-know.html Accessed on 24 February 2014

Luban D (2006) Beyond moral minimalism. Ethics Int Aff 20:353-360

Metz T (2000) Censure theory and intuitions about punishment. Law Philos 19:491-512

Willsher K, Rushe D (2011) Dominique Strauss-Kahn will fly home to a France divided over his reputation The Guardian, August 24th 2011 http://www.theguardian.com/world/2011/aug/24/dominique-strauss-kahnfrance-divided on Accessed 24 February 2014

Wringe B (2006) 'Why punish war crimes: Victor's justice and an expressive justification of punishment'. Law Philos 25:159-191

Wringe B (2012) Collective agents and communicative theories of punishment. J Soc Philos 43:436-456

Wringe B (2013) Must punishment be intended to cause suffering? Eth Theory Moral Pract 16:863-877 